\title{
Increasing vitamin D deficiency in children from 1995 to 2011
}

Ji-Hyun Seo ${ }^{1}$, Hye Jin Chung ${ }^{4}$, Hye-Jung Kim² ${ }^{2}$, Jung Sook Yeom ${ }^{1}$, Ji Sook Park ${ }^{1}$, Eun-Sil Park ${ }^{1}$, Jae-Young Lim ${ }^{1}$, Chan-Hoo Park ${ }^{1}$, Hyang-Ok Woo ${ }^{1}$, Hee-Shang Youn ${ }^{1}$, Jun-Je Park ${ }^{3}$

${ }^{1}$ Departments of Pediatrics, ${ }^{2}$ Pharmacology, and ${ }^{3}$ Otolaryngology, Gyeongsang National University School of Medicine, Gyeongsang Institute of Health Science, Jinju; ${ }^{4}$ College of Pharmacy and Research Institute of Pharmaceutical Sciences, Gyeongsang National University, Jinju, Korea.

E-mail: capetown@hanmail.net

Received: 6th November 2015, Revised: 28th December 2015, Accepted: 16th March 2017

SUMMARY: Seo JH, Chung HJ, Kim HJ, Yeom JS, Park JS, Park ES, Lim JY, Park CH, Woo HO, Youn HS, Park JJ. Increasing vitamin D deficiency in children from 1995 to 2011. Turk J Pediatr 2016; 58: 616-622.

Serum concentrations of 25-hydroxy vitamin $\mathrm{D}_{3}\left[25(\mathrm{OH}) \mathrm{D}_{3}\right]$ and vitamin $\mathrm{D}$ deficiency have changed over time in Korean children. This study assessed serum $25(\mathrm{OH}) \mathrm{D}_{3}$ concentrations and the prevalence of vitamin $\mathrm{D}$ deficiency in children. Serum samples were obtained during 1995 to 2011, and 25(OH) $\mathrm{D}_{3}$ concentrations were measured by liquid chromatography-tandem mass spectrometry (LC-MS/MS). Tests of 948 serum samples showed that median $25(\mathrm{OH}) \mathrm{D}_{3}$ concentrations decreased significantly $(\mathrm{P}<0.001)$, and the rates of vitamin $\mathrm{D}$ deficiency/insufficiency increased significantly $(\mathrm{P}<0.001)$, over 15 years. Median serum $25(\mathrm{OH}) \mathrm{D}_{3}$ was significantly higher in males than in females in 2005-2006 and 2010-2011 ( $<<0.001)$, whereas the rates of vitamin $\mathrm{D}$ deficiency/insufficiency were higher in subjects aged 11-15 years than in the other two age groups after the year 2000. These increases over time in vitamin D deficiency/insufficiency may be due to the changing lifestyles of children. Outdoor physical activity should be strongly encouraged.

Key words: vitamin $D$, vitamin $D$ deficiency, children, adolescent.

Vitamin D is a fat-soluble vitamin that is important for maintaining calcium homeostasis through actions in the intestine, bone, kidney, and parathyroid gland ${ }^{1}$. Vitamin $\mathrm{D}$ is also essential for normal growth and skeletal development ${ }^{2}$. More recently, vitamin D status has been linked to cancer, cardiovascular disease, autoimmune disease, and infection ${ }^{3}$. This vitamin is acquired through nutritional supplements (10-20\%) and by cutaneous synthesis from exposure to sunlight $(80-90 \%)^{4}$. In children, causes of rickets have changed from low exposure to sunlight and intake of vitamin $\mathrm{D}$ to inappropriate supplementation or metabolic disorders, including hepatic disease, renal disease, and metabolic problems with calcium or phosphorus. However, vitamin $\mathrm{D}$ deficiency and nutritional rickets are reemerging as a major public health problem throughout the world ${ }^{5-9}$. The prevalence of vitamin $\mathrm{D}$ deficiency in normal healthy individuals is high in many countries $6,7,9$.

Risk factors for low vitamin D status in Korean children from 2006 to 2013 have been reported to include obesity $10^{10-12}$, female gender 11,13 , low physical activity ${ }^{11,12}$, winter season ${ }^{11}$, and older age 11,14. The effects of older age on vitamin $\mathrm{D}$ deficiency regardless of weight may be due to the reduced opportunity of older Korean children to participate in outdoor activities $^{14}$.

To date, no study has assessed changes over time of vitamin D levels in Korean children. Vitamin D levels are routinely tested by measuring the serum concentration of the major circulating form of vitamin D, 25-hydroxy vitamin $\mathrm{D}_{3}\left[25(\mathrm{OH}) \mathrm{D}_{3}\right]$. This study was designed to investigate the changing pattern of serum $25(\mathrm{OH}) \mathrm{D}_{3}$ levels in children from 1990 to 2011 and to evaluate the prevalence of vitamin $\mathrm{D}$ deficiency in this population. 


\section{Material and Methods \\ Clinical samples}

The study population consisted of patients aged 1-15 years who visited the Department of Pediatrics of Gyeongsang National University Hospital (GNUH) in Jinju, Korea, from June to October of each year. As a member of the National Biobank of Korea, the GNUH collects serum samples from patients randomly and stores them at $-80^{\circ} \mathrm{C}$. Serum samples collected in 1990-1991, 1995-1996, 2000-2001, 20052006, and 2010-2011 were stratified by age groups, subjects aged $1-5$ years (preschoolers), 6-10 years (elementary school children), and 11-15 years (adolescents) (Table 1). Stored data included age, sex, diagnosis, and month of sample collection (from June to August). Patients with specific conditions, such as malignant disorders, chronic kidney disease, parathyroid disease, inflammatory bowel disease, or severe immunodeficiency, were excluded. Finally, 1008 samples were selected, 525 from boys and 483 from girls. The number of samples ranged from 60 collected in 1990-1991 to 298 samples collected in 2005-2006 and in 2010-2011 (Table 1).

Vitamin $\mathrm{D}$ deficiency has been defined as a $25(\mathrm{OH}) \mathrm{D}_{3}$ concentration $<20 \mathrm{ng} / \mathrm{ml}$, whereas vitamin $\mathrm{D}$ insufficiency has been defined as a $25(\mathrm{OH}) \mathrm{D}_{3}$ concentration of $21-29 \mathrm{ng} / \mathrm{ml}^{12}$. The $20 \mathrm{ng} / \mathrm{ml}$ cut-off was based on studies showing that lower concentrations may be associated with rickets and impaired bone development, whereas the $30 \mathrm{ng} / \mathrm{ml}$ cut-off value was the level below which parathyroid hormone levels begin to increase in adults, thereby affecting calcium absorption.

There was no detectable degradation of $25(\mathrm{OH})$ $\mathrm{D}_{3}$ in human samples stored at $-20^{\circ} \mathrm{C}$ for more than 10 years $^{15}$ or in serum samples stored for 6-24 years at $-25^{\circ} \mathrm{C}^{16}$. The extreme stability of $25(\mathrm{OH}) \mathrm{D}_{3}$ in serum is likely due to its tight binding to vitamin $\mathrm{D}$ binding protein, and the opacity of serum in tubes to ultraviolet (UV) irradiation ${ }^{15}$. Moreover, repeated freezing and thawing did not significantly affect serum concentrations of $25(\mathrm{OH}) \mathrm{D}_{3}{ }^{17}$.

\section{Measurement of serum 25(OH) $\mathrm{D}_{3}$}

Serum levels of $25(\mathrm{OH}) \mathrm{D}_{3}$ were measured by liquid chromatography-tandem mass spectrometry (LC-MS/MS), a method simpler, and with greater rapidity, accuracy, sensitivity, and cost-effectiveness, than commercial radioimmunoassays ${ }^{18}$. Another important advantage of the LC-MS/MS method is its ability to separate $25(\mathrm{OH}) \mathrm{D}_{3}$ and $25(\mathrm{OH}) \mathrm{D}_{2}$ 18. The LC-MS/MS system consisted of an Agilent 1260 HPLC system (Agilent, Germany) with an Agilent 6460 triple quadrupole mass spectrometer (Agilent, Singapore) equipped with an electrospray ionization source. Calibration curves of $25(\mathrm{OH}) \mathrm{D}_{3}$ were linear over the ranges studied, with $\mathrm{r}^{2}>0.999$. The coefficients of variations of the $25(\mathrm{OH}) \mathrm{D}_{3}$ (intra-batch and inter-batch) were below $6.12 \%$, and the accuracy ranged from $90.8 \%$ to $113 \%$. Cut-off values for serum $25(\mathrm{OH}) \mathrm{D}_{3}$ were set at $20 \mathrm{ng} / \mathrm{ml}$ (deficiency) and $30 \mathrm{ng} /$ mll(insufficiency).

\section{Statistical analysis}

All statistical analyses were performed by using IBM SPSS 21 Statistics 1 software (IBM, USA). Serum $25(\mathrm{OH}) \mathrm{D}_{3}$ concentrations are reported as mean and standard deviation (SD). The normality and equality of variances of $25(\mathrm{OH})$ $\mathrm{D}_{3}$ were tested using the Shapiro-Wilk test and Levene's test, respectively. Linear changes in mean $25(\mathrm{OH}) \mathrm{D}_{3}$ concentrations were analyzed by the General Linear Model (GLM) method when the rates of vitamin $\mathrm{D}$ deficiency and insufficiency differed over time among all subjects or by age or sex. Differences among age groups in mean serum $25(\mathrm{OH}) \mathrm{D}_{3}$ over the total time period were assessed by analysis of variance (ANOVA). Changes in rates of vitamin $D$ deficiency and insufficiency in the total population, age group, and sex were analyzed using the linear trend test. Differences in serum $25(\mathrm{OH}) \mathrm{D}_{3}$ concentrations among age groups and by sex were determined using the $X^{2}$-test.

\section{Ethics Statement}

The study protocol was approved by the Institutional Review Board of the GNUH (GNUHIRB-2013-02-002). An agreement exemption was applied because the serum samples included no genetic information and were derived from the National Biobank of Korea. Thus, under institutional review board-approved protocols, these samples were obtained with informed consent.

\section{Results}

A total of 948 serum samples from children 
aged 1 to 15 years were tested (Table 1 ). The mean concentrations of serum $25(\mathrm{OH}) \mathrm{D}_{3}$ decreased significantly over time $(\mathrm{P}<0.001)$, being $37.5 \mathrm{ng} / \mathrm{ml}$ in $1995-1996,34.9 \mathrm{ng} / \mathrm{ml}$ in $2000-2001,31.4 \mathrm{ng} / \mathrm{ml}$ in $2005-2006$, and $22.5 \mathrm{ng} / \mathrm{ml}$ in 2010-2011. Mean serum 25(OH) $\mathrm{D}_{3}$ concentrations decreased in all age groups from 1995-1996 to 2010-2011 (P<0.001). Excluding 1995-1996, the mean level of serum $25(\mathrm{OH}) \mathrm{D}_{3}$ decreased as subject age increased $(\mathrm{P}<0.001$, Fig. 1).

Mean serum $25(\mathrm{OH}) \mathrm{D}_{3}$ concentrations were higher in males than in females among total subjects $(\mathrm{P}<0.001$, Fig. 2). The mean level and distribution of serum $25(\mathrm{OH}) \mathrm{D}_{3}$ were similar in males and females during 1995$1996(\mathrm{P}=0.420)$ and $2000-2001 \quad(\mathrm{P}=0.478)$, but were lower in females after 2005-2006 $(\mathrm{P}<0.001$, Table 1). After 2000-2001, the mean level of serum $25(\mathrm{OH}) \mathrm{D}_{3}$ was lowest in the $11-15$ years' age group $(\mathrm{P}<0.001$, Fig. $1)$, being particularly lower in this age group in 2010-2011 than in the other three periods.

The proportions of subjects with vitamin D deficiency increased from 1995-1996 to 2010-2011 ( $\mathrm{P}<0.001$, Fig.3), being $3.6 \%$ in $1995-1996,10.7 \%$ in $2000-2001,15.1 \%$ in 2005-2006, and $38.6 \%$ in 2010-2011. Similarly, the proportions of vitamin D insufficiency increased, being $26.4 \%, 28.5 \%, 30.5 \%$, and $45.0 \%$, respectively, during these four time periods. The proportion of subjects with vitamin $\mathrm{D}$ deficiency and insufficiency was highest in the 11-15 yrs. age group after 2000. In 2010-2011, 93.0\% of children aged $11-15$ yrs. and $90.9 \%$ of children aged 6-10 yrs. had vitamin D deficiency or insufficiency. The proportion of subjects with vitamin D deficiency and insufficiency increased with age $(\mathrm{P}<0.001)$ and was significantly higher in females than in males regardless of study period $(\mathrm{P}<0.001$, Table 2$)$.

\section{Discussion}

These results show that, from 1995 to 2011, serum concentrations of $25(\mathrm{OH}) \mathrm{D}_{3}$ have declined significantly, while the rates of vitamin $\mathrm{D}$ deficiency and insufficiency have increased significantly in Korean children aged 1 to 15 yr. After 2000, the prevalence of vitamin D deficiency and insufficiency was significantly higher in subjects aged 11-15 yrs. than in the other two age groups.

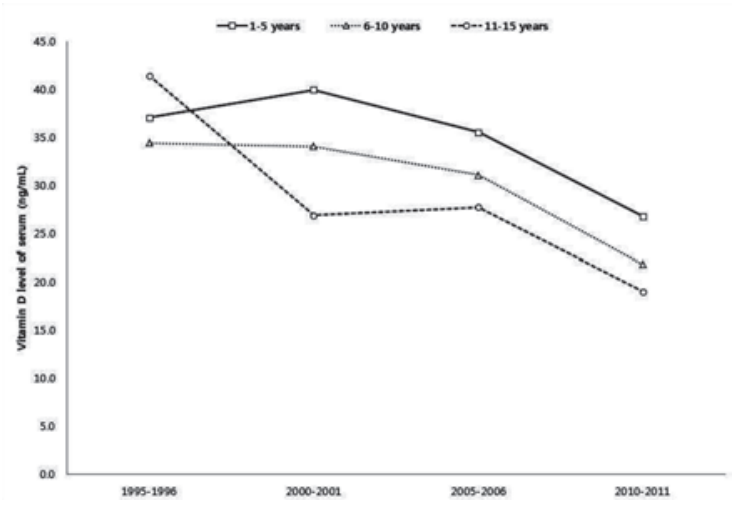

Fig. 1. Mean serum $25(\mathrm{OH}) \mathrm{D}_{3}$ concentrations according to age groups during four sampling periods between 1995-1996 and 2010-2011. Mean serum 25(OH) $\mathrm{D}_{3}$ began to decrease from 1995-1996 to 2010-2011 and was significantly lower in 2010-2011 than in the other time periods $(\mathrm{P}<0.001)$.

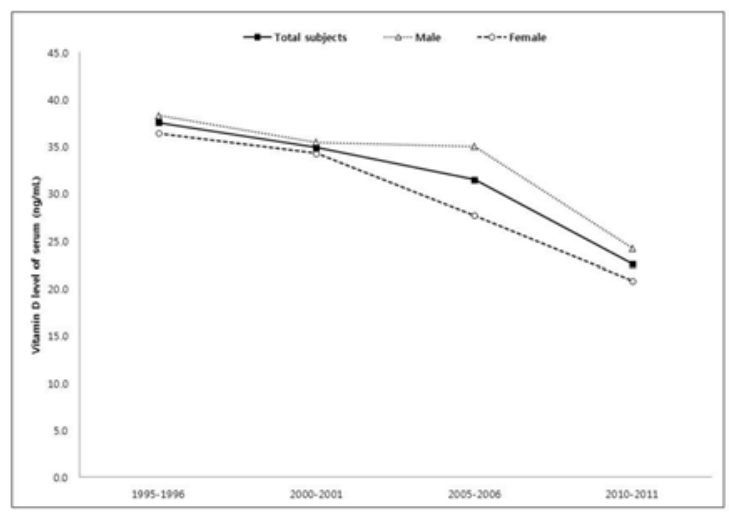

Fig. 2. Mean serum $25(\mathrm{OH}) \mathrm{D}_{3}$ concentrations according to gender during four sampling periods. Mean serum $25(\mathrm{OH})$ $\mathrm{D}_{3}$ was significantly higher in males than in females in 2005-2006 and in 2010-2011 $(\mathrm{P}<0.001)$.

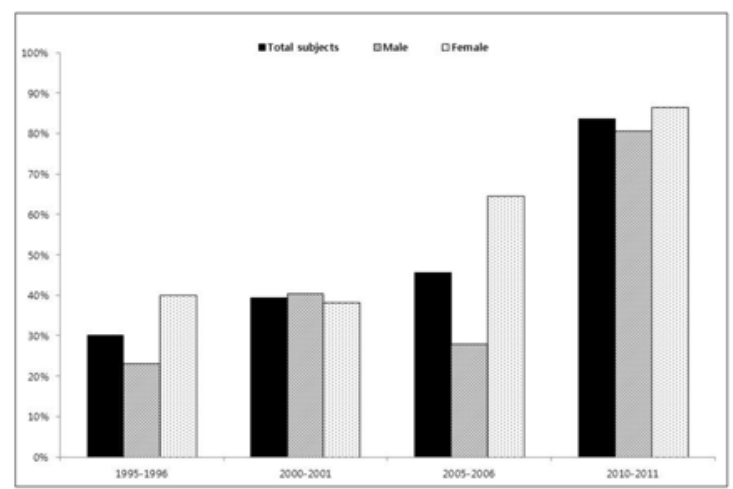

Fig. 3. Mean serum $25(\mathrm{OH}) \mathrm{D}_{3}$ concentrations according to gender during four sampling periods. Mean serum $25(\mathrm{OH})$ $\mathrm{D}_{3}$ was significantly higher in males than in females in 2005-2006, and in 2010-2011 $(\mathrm{P}<0.001)$. 


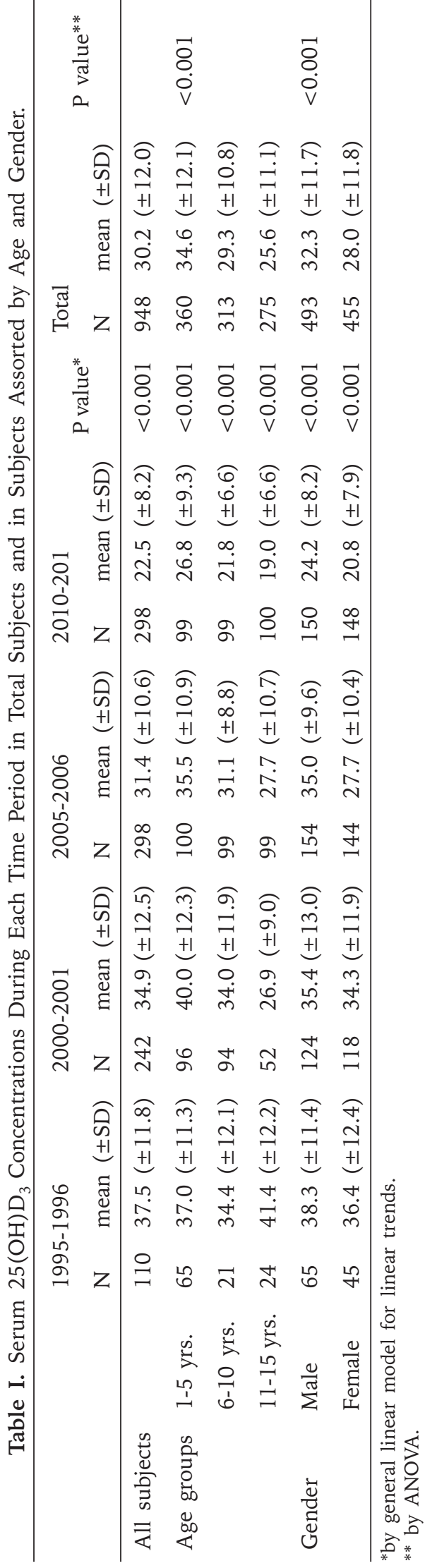

The major source of vitamin D for children and adults is exposure to natural sunlight ${ }^{19-21}$. Very few foods naturally contain or are fortified with vitamin $\mathrm{D}$. Thus, the major cause of vitamin $\mathrm{D}$ deficiency is inadequate exposure to sunlight ${ }^{22}$. Among these children, the highest median serum $25(\mathrm{OH}) \mathrm{D}_{3}$ concentrations and the lowest prevalence of vitamin D deficiency were found in 1995-1996 compared with the other three periods. The southern part of Korea experienced a severe drought from February 1994 to March 1996 due to extreme summer weather events ${ }^{23}$. In Jinju, the cumulative hours of sunshine were longest and the amount of precipitation were smallest during the summer of 1995 than in the other years studied (Meterological Database, Korea Meterological Administration).

A study of 1,212 Korean children aged 4 to 15 years from 2012 to 2013 found that rates of vitamin $\mathrm{D}$ deficiency increased with age, being $44.3 \%, 56.8 \%, 63.0 \%$, and $77.0 \%$ in children aged $4-6,7-9,10-12$, and 13-15 years, respectively ${ }^{14}$. This study also found that vitamin $\mathrm{D}$ deficiency increased with age since 2000 , and that the median serum $25(\mathrm{OH}) \mathrm{D}_{3}$ concentration was lower in subjects aged 11-15 yrs. than in those aged 1-5 and 6-10 yrs. A study using data from The Korean National Health and Nutrition Examination Survey (KNHANES) 2008-2009 reported that the risk factors for low vitamin D concentration in 1,510 healthy adolescents aged 12-18 years were winter season, older age, higher educational level, female gender, obesity, lack of vitamin D supplementation, lower milk consumption, and lack of physical activity ${ }^{11}$. The serum samples in this study were obtained from the National Biobank; thus clinical data, such as body weight, vitamin $\mathrm{D}$ supplementation, milk consumption, and physical activity, were unavailable for the study population. However, our finding that the prevalence of vitamin D deficiency was higher in adolescents than in younger children might be related to the tendency of Korean adolescents to limit outdoor activities as they prepare for entrance into high-ranking schools ${ }^{24}$.

The time spent by Korean adolescents in screen-based sedentary activities has increased dramatically in the past decade ${ }^{24}$. At present, Korean adolescents spend most of their free time in after-school programs/tutoring (57.9\%), staying home $(15.9 \%)$, and online gaming 
$(10.2 \%)^{25}$. The prevalence of internet usage among Korean adolescents aged 16 to 19 yrs. has increased dramatically, from about $50 \%$ in 1999 to $90.6 \%$ in 2002, almost reaching the market saturation point ${ }^{26}$. Internet usage by children aged 6-10 yrs. may be associated with the increased prevalence of vitamin $\mathrm{D}$ deficiency over time, from $9.1 \%$ in $2005-2006$ to $38.4 \%$ in $2010-2011$.

Another potential cause of increased vitamin D deficiency and insufficiency may be increased sunscreen use by children. Sunscreens block the cutaneous absorption of UV-B radiation, thus interfering with vitamin $\mathrm{D}_{3}$ synthesis in the skin 25,26 . In agreement with previous findings ${ }^{27-29}$, our study found that the prevalence of vitamin D deficiency or insufficiency was higher in girls than in boys. Korean girls have been reported to engage in lower levels of physical activity and have lower calcium intake than Korean boys ${ }^{29}$. Girls are also more likely to use sunscreen. Serum 25(OH)D concentrations showed a negative correlation with soft drink intake in Korean schoolgirls ${ }^{30}$. Even in summer, $84 \%$ of 205 Korean children aged 7 to 9 yrs. had serum $25(\mathrm{OH}) \mathrm{D}_{3}$ concentrations under $30 \mathrm{ng} / \mathrm{ml}$ in $2011^{12}$, which may be related to sunscreen use.

This study found that the prevalence of vitamin $\mathrm{D}$ deficiency was lower in subjects aged 1-5 yrs. than in those aged 6-10 and 11-15 yrs. Few studies have assessed vitamin $\mathrm{D}$ deficiency in Korean children under the age of 5 years. Two studies reported that vitamin D deficiency in infants aged 1 to 6 months and in normal children under age 24 months was associated with breastfeeding 31,32 . Since clinical data, including nutritional status, could not be evaluated in our study population, we could not determine the reason for the lower rate of vitamin $\mathrm{D}$ deficiency in children aged 1-5 yrs. than in older children. However, children aged 1-5 yrs. may spend more time outdoors and participate in a greater degree of physical activity than children aged 6-15 yrs.

Serum concentrations of $25(\mathrm{OH}) \mathrm{D}_{3}$ have been reported to be inversely associated with body mass index, waist circumference, and body fat mass ${ }^{12}$, a finding consistent with the results of the KNHANES 2008-2009 study ${ }^{11}$. In Korea, height, weight, and body mass index have increased dramatically from 1965-1997 to 
1997-200733. Increases in height and weight may have influenced $25(\mathrm{OH}) \mathrm{D}_{3}$ concentrations among our study population, although this information was not available.

Childhood vitamin D deficiency may be an important health problem because vitamin $\mathrm{D}$ is essential for normal growth and skeletal development ${ }^{2}$. Moreover, childhood vitamin $\mathrm{D}$ deficiency has been associated with the development of diabetes and metabolic syndrome in adults ${ }^{34}$. The levels of insulin, homeostasis model assessment of insulin resistance (HOMA-IR) score, and systolic blood pressure were found to be higher in Korean girls with than without vitamin $\mathrm{D}$ deficiency ${ }^{30}$. Moreover, serum $25(\mathrm{OH}) \mathrm{D}_{3}$ levels were inversely associated with HOMA-IR score and concentrations of triglycerides, and low-density lipoprotein cholesterol in Korean adolescents aged 12-13 yrs. ${ }^{13}$.

Vitamin D deficiency in children may be prevented by vitamin supplementation and participation in outdoor activities. In addition, fortification of foods with vitamin $\mathrm{D}$ may be effective. Appropriate guidelines for the use of topical sunscreen in children should also be established to minimize the effects of sunscreen on cutaneous vitamin D production. Schools should also change their policies and guidelines to promote outdoor activities.

This study had several limitations. First, the small sample size and the different sizes of the study subgroups may have influenced the statistical analysis. Second, the nutritional status and clinical data, including body weight, height, and body mass index, were not available. In addition, our subject sample was drawn from one geographic region in Korea, and the data were acquired from independent random samples collected for 20 years rather than from a longitudinal cohort study, precluding a determination of factors associated with vitamin $\mathrm{D}$ deficiency, such as insufficient dietary vitamin D intake, sunlight exposure time, or outdoor activity time. Further epidemiologic studies assessing factors associated with serum vitamin $\mathrm{D}$ levels in children may provide insight into this condition.

However, this study also had several strengths. For example, assessment of serum samples collected over 20 years enabled a determination of trends in serum vitamin $\mathrm{D}$ concentrations in children over time. Although previous studies have reported a high prevalence of vitamin $\mathrm{D}$ deficiency in Korean adolescents, this study, to our knowledge, is the first to evaluate secular trends in serum vitamin $D$ levels in Korean children for two decades. Our findings clearly indicate that the prevalence of vitamin $\mathrm{D}$ deficiency is increasing in children in urban areas in Korea. Our data have important implications for public health recommendations.

In conclusion, this study showed that vitamin $\mathrm{D}$ deficiency or insufficiency in children and adolescents in Jinju, Korea, increased from 1995-1996 to 2010-2011, while mean serum vitamin D concentrations decreased, especially in adolescents. These results may be associated with changing lifestyles among Korean children and suggest that outdoor physical activity and sufficient vitamin $\mathrm{D}$ intake should be strongly encouraged in these children.

\section{Acknowledgments}

The biospecimens used in this study were provided by the Gyeongsang National University Hospital, a member of the Korean Biobank Network. All samples were obtained following approval from the Gyeongsang National University Hospital Institutional Review Board.

This work was supported by Biomedical Research Institute Fund "GRUHBRIF-2013-0001" from the Gyeongsang National University Hospital.

\section{REFERENCES}

1. Feldman D MP, Krishnan AV, Balint E. Vitamin D: Biology, action and clinical implications. In: Marcus R FD, Nelson DA (ed). Osteoporosis (3rd ed). San Diego: CA: Academic Press, 2007: 317-382.

2. Misra M, Pacaud D, Petryk A, Collett-Solberg PF, Kappy M. Vitamin D deficiency in children and its management: review of current knowledge and recommendations. Pediatrics 2008; 122: 398-417.

3. Souberbielle JC, Body JJ, Lappe JM, et al. Vitamin D and musculoskeletal health, cardiovascular disease, autoimmunity and cancer: Recommendations for clinical practice. Autoimmun Rev 2010; 9: 709-715.

4. Holick MF. Evolution, biologic functions, and recommended dietary allowances for vitamin D. In: Holick MF (ed). Vitamin D: Physiology, Molecular Biology and Clinical Applications. Totowa: NJ: Humana Press, 1999: 1-16.

5. Holick MF. Vitamin D deficiency. N Engl J Med 2007; 357: 266-281.

6. Chapuy MC, Schott AM, Garnero P, Hans D, Delmas PD, Meunier PJ. Healthy elderly French women living at home have secondary hyperparathyroidism and high 
bone turnover in winter. EPIDOS Study Group. J Clin Endocrinol Metab 1996; 81: 1129-1133.

7. Marwaha RK, Tandon N, Reddy DR, et al. Vitamin $\mathrm{D}$ and bone mineral density status of healthy schoolchildren in northern India. Am J Clin Nutr 2005; 82: 477-482.

8. Thacher TD, Fischer PR, Strand MA, Pettifor JM. Nutritional rickets around the world: causes and future directions. Ann Trop Paediatr 2006; 26: 1-16.

9. Ozkan B, Doneray H, Karacan M, et al. Prevalence of vitamin $\mathrm{D}$ deficiency rickets in the esstern part of Turkey. Eur J Pediatr 2009; 168: 95-100.

10. Lee SH, Kim KS, Park HS, et al. Serum 25-hydroxyvitamin $\mathrm{D}$ levels, obesity and the metabolic syndrome among Korean children. Nutr Metab Cardiovasc Dis 2013; 23: 785-791.

11. Lee YA, Kim HY, Hong H, et al. Risk factors for low vitamin D status in Korean adolescents: the Korea National Health and Nutrition Examination Survey (KNHANES) 2008-2009. Public Health Nutr 2014; 17: 764-771.

12. Lee HA, Kim YJ, Lee $\mathrm{H}$, et al. Association of vitamin D concentrations with adiposity indices among preadolescent children in Korea. J Pediatr Endocrinol Metab 2013; 26: 849-854.

13. Shin $\mathrm{YH}$, Kim KE, Lee $\mathrm{C}$, et al. High prevalence of vitamin D insufficiency or deficiency in young adolescents in Korea. Eur J Pediatr 2012; 171: 14751480 .

14. Chung IH, Kim HJ, Chung S, Yoo EG. Vitamin D deficiency in Korean children: Prevalence, risk factors, and the relationship with Parathyroid hormone levels. Ann Pediatr Endocrinol Metab 2014; 19: 86-90.

15. Hollis BW. Measuring 25-hydroxyvitamin D in a clinical environment: Challenges and needs. Am J Clin Nutr 2008; 88: 507S-510S.

16. Agborsangaya C, Toriola AT, Grankvist K, et al. The effects of storage time and sampling season on the stability of serum 25-hydroxy vitamin D and androstenedione. Nutr Cancer 2010; 62: 51-57.

17. Antoniucci DM, Black DM, Sellmeyer DE. Serum 25-hydroxyvitamin $\mathrm{D}$ is unaffected by multiple freezingthaw cycles. Clin Chem 2004; 51: 258-260.

18. van den Ouweland JM, Beijers AM, Demacker PN, van Daal H. Measurement of 25-OH-vitamin D in human serum using liquid chromatography tandem-mass spectrometry with comparison to radioimmunoassay and automated immunoassay. J Chromatogr B Analyt Technol Biomed Life Sci 2010; 878: 1163-1168.

19. Holick MF. Vitamin D: A millennium perspective. J Cell Biochem 2003; 88: 296-307.
20. Holick MF. Resurrection of vitamin D deficiency and rickets. J Clin Invest 2006; 116: 2062-2072.

21. Hess AF, Unger LJ. The cure of infantile rickets by sunlight. JAMA 1921; 77: 39-41.

22. Holick MF, Binkley NC, Bischoff-Ferrari HA, et al Evaluation, treatment, and prevention of vitamin D deficiency: an Endocrine Society clinical practice guideline. J Clin Endocrinol Metab 2011; 96: 19111930.

23. Kim DW, Byun HR, Choi KS, Oh SB. A spatiotemporal analysis of historical droughts in Korea. J Appl Meteorol Clim 2011; 50: 1895-1912.

24. Lee M, Larson R. The Korean "examination hell": Long hours of studying, distress, and depression. J Youth Adolescence 2000; 29: 249-271.

25. Matsuoka LY, Ide L, Wortsman J, MacLaughlin JA, Holick MF. Sunscreens suppress cutaneous vitamin D3 synthesis. J Clin Endocrinol Metab 1987; 64: 11651168.

26. Chen TC, Chimeh F, Lu Z, et al. Factors that influence the cutaneous synthesis and dietary sources of vitamin D. Arch Biochem Biophys 2007; 460: 213-217.

27. Kumar J, Muntner P, Kaskel FJ, Hailpern SM, Melamed ML. Prevalence and associations of 25-hydroxyvitamin D deficiency in US children: NHANES 2001-2004. Pediatrics 2009; 124: e362-e370.

28. El-Hajj Fuleihan G, Nabulsi M, Choucair M, et al Hypovitaminosis D in healthy schoolchildren. Pediatrics 2001; 107: E53.

29. Kim SH, Oh MK, Namgung R, Park MJ. Prevalence of 25-hydroxyvitamin D deficiency in Korean adolescents: association with age, season and parental vitamin D status. Public Health Nutr 2014; 17: 122-130.

30. Jang HB, Lee HJ, Park JY, Kang JH, Song J. Association between serum vitamin D and metabolic risk factors in Korean schoolgirls. Osong Public Health Res Perspect 2013; 4: 179-186

31. Moon JS. Reappraisal of Regional Growth Charts in the Era of WHO Growth Standards. Pediatr Gastroenterol Hepatol Nutr 2013; 16: 137-142.

32. Morrison JA, Friedman LA, Wang P, Glueck CJ Metabolic syndrome in childhood predicts adult metabolic syndrome and type 2 diabetes mellitus 25 to 30 years later. J Pediatr 2008; 152: 201-206.

33. Jin HJ, Lee JH, Kim MK. The prevalence of vitamin D deficiency in iron-deficient and normal children under the age of 24 months. Blood Res 2013; 48: 40-45.

34. Choi YJ, Kim MK, Jeong SJ. Vitamin D deficiency in infants aged 1 to 6 months. Korean J Pediatr 2013; 56: $205-210$. 